\title{
Nutritional intervention in infantile colic: mini review
}

\begin{abstract}
Background: Infantile colic is a severe irritable or crying which bothers babies and parents. The etiology of infantile colic is not known until now and nutritional intervention is often used as a treatment for colic symptom.
\end{abstract}

Objective: To determine the role of nutrition in the management of infantile colics.

Method: This review article on infantile colic used several electronic databases such as Google, Pubmed, Ebscohost, American Academy of Pediatrics Publications and Cochrane databases

Results: Three studies of infantile colic on breast-fed infants and six studies of infantile colic on infants who consumed formula milk were found.

Conclusion: Low-allergen diet consumption in mothers who breast-fed infants or infants who consumed extensive hydrolyzed casein-based formula can improve symptom of infantile colic. There is no strong evidence for now to recommend the use of soy protein-based formulas and low-lactose formula as the management of infantile colic in infants.

Keywords: infantile colic, nutritional intervention.
Volume 3 Issue 3 - 2017

\author{
Lanny Christine Gultom,' Damayanti Rusli \\ Sjarif ${ }^{2}$ \\ 'Division of Nutrition and Metabolic Diseases, Child Health \\ Department - Fatmawati Hospital, Indonesia \\ ${ }^{2}$ Division of Nutrition and Metabolic Diseases, Child Health \\ Department of Universitas Indonesia -Ciptomangunkusumo \\ Hospital, Indonesia
}

\begin{abstract}
Correspondence: Damayanti R Sjarif, Division of Nutrition and Metabolic Diseases, Child Health Department of

Universitas Indonesia - Ciptomangunkusumo Hospital, Central
\end{abstract} of Jakarta, Indonesia, Email ukk.npm.idai@gmail.com

Received: November 27, 2017 | Published: December 18, 2017

\section{Introduction}

Infantile colic is a symptomatic disorder characterized by paroxysms of fussing, agitation or crying, lasting more than three hours a day and occurring more than three days a week for at least three weeks. ${ }^{1}$ In addition to this definition, diagnostic criteria of Rome III for functional gastrointestinal disorder defines infantile colic as a condition that includes all of the following symptoms in infants aged less than 4months, such as (1) paroxysms of irritability, fussing or crying that start and stop without obvious cause, (2) episodes lasting for three or more hours per day and occurring at least three days per week for at least one week, and (3) there is no failure to thrive. ${ }^{2}$ The main symptoms are excessive and persistent crying which tend to occur at night. During each episodes, the child appears distress, irritable, fussy, becomes red faces, contracted legs, and frequent borborygmi. ${ }^{3}$ This condition occurs in $10-40 \%$ of infants worldwide and peaks at around 6 weeks, then disappears by $3-6$ months. The incidence of infantile colic is similar in both male and female infants. There are also no relationships between infantile colic and feeding types (breastfed or formula), gestational age, or socioeconomic status. The definite cause of infantile colic is unknown. Several causes of infantile colic have been proposed such as microfloral changes in faecal content, cow's milk or lactose intolerance, gastrointestinal immaturity or inflammation, increased serotonin secretion, inappropriate breastfeeding techniques, and maternal smoking or nicotine replacement therapy. ${ }^{4}$

Infantile colic is a diagnosis of exclusion; established only after careful history and physical examination have excluded some dangerous causes including morbus hirschprung, incarcerated hernia, testicular torsion, child abuse, gastroesophageal reflux disease, pyloric stenosis, anal fissures, etc. Parental support and reassurance are key components of colic management. ${ }^{4}$ Various studies have analyzed the management of infantile colic with mixed results. These include: (1) probiotic Lactobacillus reuteri (strain DSM 17938), drugs such as simethicone, dicyclomine, and proton pump inhibitors, (3) dietary modification, (4) physical therapy including chiropractic and osteopathic manipulation, massage, and acupuncture, (5) herbal therapy including Mentha piperita (peppermint) and various other herbal teas such as fennel, chamomile, vervain, lemon balm, and licorice, and (6) other modalities including $12 \%$ sucrose solution, "Gripe water" which consists of dill seed oil, bicarbonate, and hydrogenated glucose, the use of a vented bottle or swaddling. ${ }^{4}$ This review only discusses the role of nutrition in the management of infantile colic.

\section{Methods}

This review used Google, Pubmed, Ebscohost, American Academy of Pediatrics Publications and Cochrane databases with infant and colic as the keywords. The inclusion criteria in this review were studies which involved infant as the subject's research and had been published during 1980 - 2016. The studies included in this review were studies that met the inclusion criteria and focuses only on infants who were breast-fed and infants receiving hydrolyzed protein-based formula, soy protein-based formula, and low-lactose formula.

\section{Results}

There were 3 studies on infants with infantile colic who were breast-fed and 6 studies on infants with infantile colic who received formula milk (Table 1) (Table 2). Studies on nutritional intervention as the management of infantile colic in breast-fed infants showed various results (Table 1). Jakobsson et al. ${ }^{5}$ Hill et al. ${ }^{6}$ and Hill et al. ${ }^{7}$ showed that there were improvements of colic symptoms in breastfed infants if mother avoided cow's milk, eggs, peanuts, wheat, 
soy, and fish in their diet (low-allergen diet). Several studies which used infant formula as nutritional intervention in infants suffering from infantile colic also gave varying results (Table 2). Studies by Lothe et al. ${ }^{8}$ Lothe et al. ${ }^{9}$ Lucassen et al. ${ }^{10}$ and Savino et al. ${ }^{11}$ that used hydrolyzed casein-based formula (Nutramigen) or hydrolyzed whey-based formula showed improvements of colic symptoms and crying duration. However, the administration of capsules containing whey powder extracted from cow's milk caused colic symptoms

Table I Studies on the effect of diet in breast-fed infants to reappear in $75 \%$ of infants who showed improvement of colic symptoms after consumption of hydrolyzed casein-based formula (Nutramigen). ${ }^{9}$ Consumption of soy protein-based formula either resulted in improvement of colic symptoms in $18 \%$ of infants with colics $^{8}$ or reduced duration of colic symptoms, ${ }^{12}$ whereas Infante et al. ${ }^{13}$ showed in their study improvement in excessive gas production, abnormal feeding pattern, and crying duration in infants with colics who received low lactose-based formula for 15days.

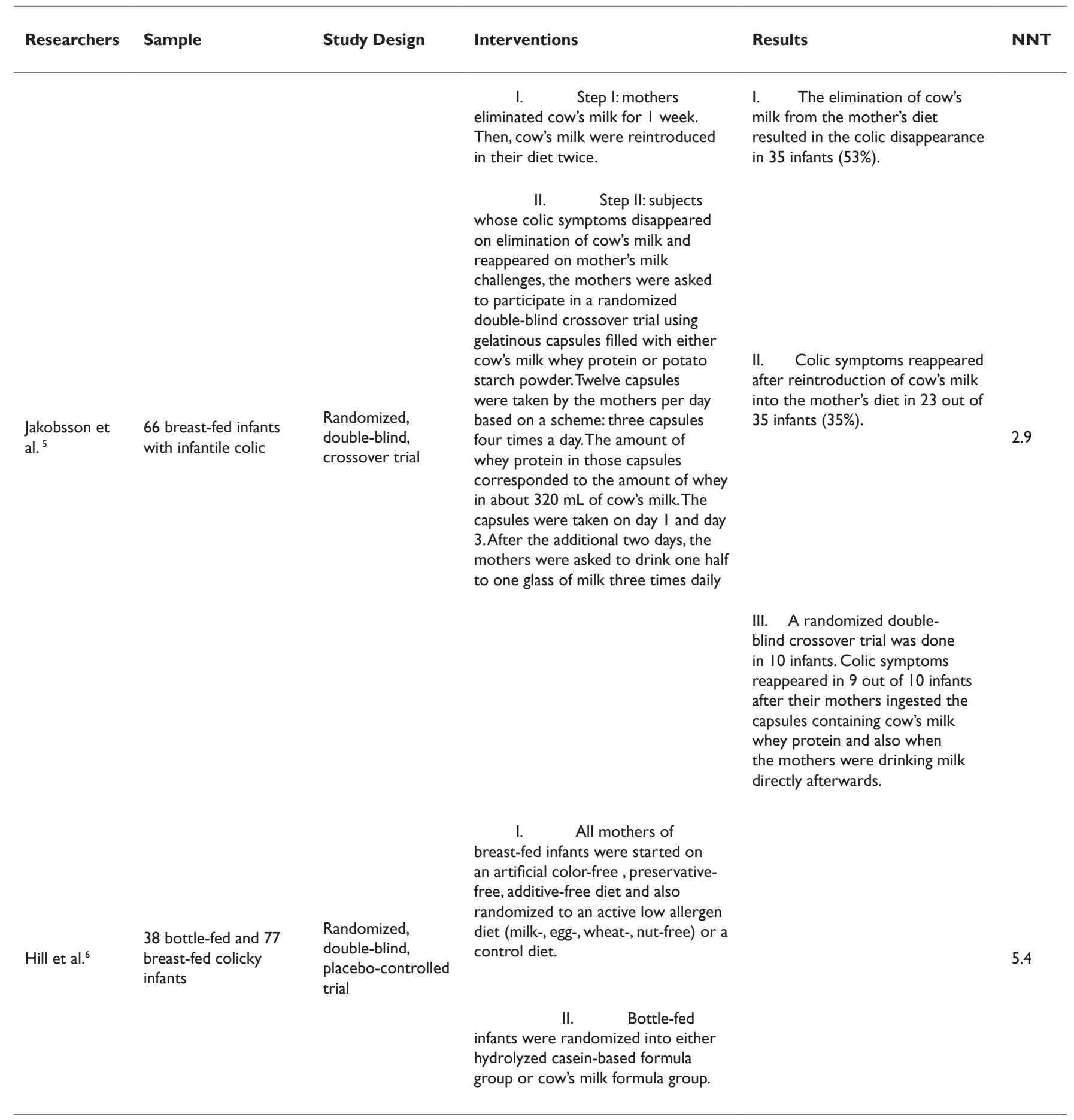


Table Continued...

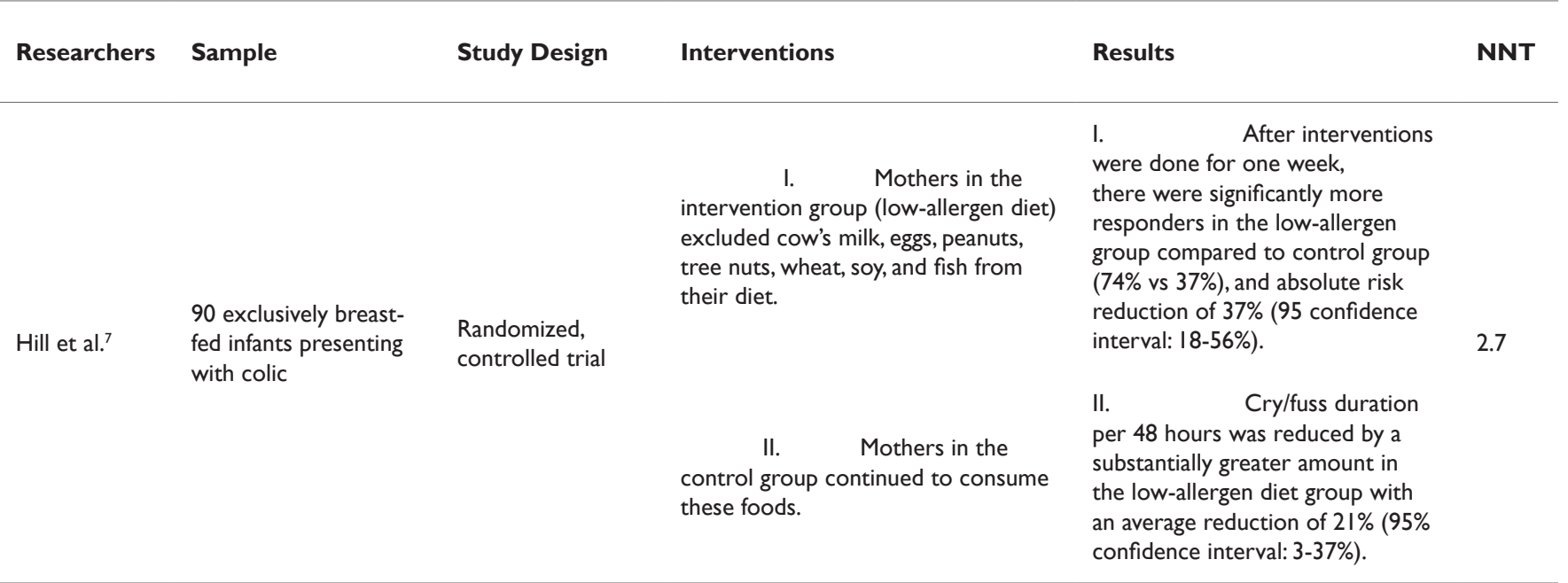

Note NNT,Number Needed to Treat

Table 2 Studies on the effect of diet in infants who received formula milk

Researchers Sample

Study design

Interventions

Results

NNT

\section{Hypoallergenic formula}

I. 60 colicky infants were given a cow's milk- and soybased formula

II. Hydrolyzed caseinbased formula were given to infants whose symptoms were unchanged or worse when they were fed cow's milk- and soy-based formula.

Lothe et al. ${ }^{8} \quad 60$ colicky infants Double-blind study
II. Symptoms of 32 (53\%) infants were unchanged or worse when they were fed cow's milk- and soy-based formula, but symptoms disappeared when they were fed hydrolyzed casein-based formula (Nutramigen).

III. Symptoms of 17 (29\%) infants were not related to the diet, so these infants continued to consume cow's milk-based formula.

IV. Challenges with cow's milk-based formula at 3 , 6 , and 12 months of age caused infantile colic symptoms in 22 (36\%), II (I8\%), and 8 (I3\%). 
Table Continued...

Researchers Sample

\section{Hypoallergenic formula}

Lothe et al. ${ }^{9}$
27 infants with severe colic
43 healthy, formulaLucassen et feds infants aged $<6$ al. ${ }^{10}$ months old with infantile colic
Randomized, doubleblind, parallel trial
I. casein-based formula (Nutramigen).

II. Infants whose colic symptoms disappeared after receiving hydrolyzed casein-based formula (Nutramigen) were given one identical capsule and mixed it into the bottle of Nutramigen (capsule A) at each meal five times a day on the sixth day. For the second challenge, the same procedure was performed with capsule $B$ on the tenth day

\section{Capsule A contained} $135 \mathrm{mg}$ of bovine whey protein powder containing $90 \mathrm{mg}$ of whey protein, $26 \mathrm{mg}$ of carbohydrates, 2 $\mathrm{mg}$ of fat, electrolytes, and minerals. Capsule B contained I 35 mg of human albumin powder used as placebo. Nutramigen was added to a weight of $200 \mathrm{mg}$ to each capsule.

IV. The amount of whey protein in five capsules corresponded to the amount in about $70 \mathrm{~mL}$ of whole cow's milk

I.

24 out of 27

infants who received hydrolyzed casein-based formula had the reduced symptoms of crying, gasformation, hiccup, and disturbed sleep compared to cow's milkbased formula $(p<0.001)$.

II. 18 infants receiving the whey protein-containing capsules reacted with colic, 2 infants receiving placebo reacted with colic $(p<0.00 \mathrm{I})$, and 4 infants did not react at all

III. Crying hours per day for the 24 infants receiving cow's milk-based protein and hydrolyzed casein-based formula were 5.6 hours and 0.7 hours $(P$ $<0.001$ ).

IV. Crying hours per day for the infants receiving whey protein capsules and placebo were 3.2 hours and 1.0 hour ( $P$ $<0.00$ I)

II. Around 5 out of 43 infants were withdrawn during the intervention week because of less data.

I. 20 infants were fed hydrolyzed whey-based formula and 18 infants were fed cow's milkbased formula.
III. After adjusted for the confounders in 38 infants, such as infant's gender and the duration of crying during the qualification period, the difference of the decrease in crying time between hydrolyzed whey-based protein and cow's milk-based protein was 47 minutes/day ( $\mathrm{p}$ $=0.04$ ) 
Table Continued.

Study design

Interventions

Results

NNT

\section{Hypoallergenic formula}

267 formula-fed infants, aged $<4$ months old with infantile colic

\section{Prospective}

Savino et al. ${ }^{\prime \prime}$

\section{randomized}

controlled trial received new formula containing partially hydrolyzed formula supplemented with fructo- and galacto-oligosaccarides and high palmitic acid for 14 days.

II. Control group received standar formula and $6 \mathrm{mg} /$ $\mathrm{kg}$ of simethicone twice daily.
I. infants who 96 infants were treated with the new formula and 103 infants were not treated.

II. On day 7 , infants receiving the new formula had a significant decrease in colic episodes ( $2.47 \pm \mathrm{I} .94$ at day 7 vs $5.99 \pm 1.84$ at the study entry) compared to infants receiving the standard formula $(3.72 \pm 1.98$ at day 7 vs $5.4 \mathrm{I} \pm \mathrm{I} .88$ at the study entry) $(p<0.000 \mathrm{I})$.

III. On day 14 , the crying episodes were clinically different between the two groups of infants ( $1.76 \pm 1.60$ in intervention group vs $3.32 \pm 2.06$ in control group) $(p<0.0001)$

\section{Soy protein-based formula}

$\begin{array}{lll}\text { Campbell }^{12} & \begin{array}{l}19 \text { infants with } \\ \text { infantile colic }\end{array} & \begin{array}{l}\text { Randomized, double- } \\ \text { blind, crossover trial }\end{array}\end{array}$

10 infants were given soya milk for one week followed by standard modified cow's milk formula in the following week, and 9 infants had standard milk followed by soya milk
I. The duration of colic symptoms was significantly reduced during the week on soya milk $(\mathrm{p}<0.0 \mathrm{I})$.

\section{II.} infants with colic symptoms who received intervention; I I $(58 \%)$ infants had intolerance of cow's milk, 2 (I I\%) infants had intolerance of cow's milk and soya milk, 5 (26\%) infants had spontaneous resolved symptoms, and I (5\%) infants had failure of dietary treatment 
Table Continued..

\begin{tabular}{|c|c|c|c|c|c|}
\hline Researchers & Sample & Study design & Interventions & Results & NNT \\
\hline \multicolumn{6}{|c|}{ Low-lactose formula } \\
\hline \multirow{4}{*}{ Infante et al. ${ }^{13}$} & \multirow{4}{*}{20 colicky infants } & \multirow{4}{*}{$\begin{array}{l}\text { Non-randomized, } \\
\text { non-placebo- } \\
\text { controlled study }\end{array}$} & \multirow{4}{*}{$\begin{array}{l}\text { All infants received an adapted } \\
\text { low-lactose formula (Novalac AC) } \\
\text { for } 15 \text { days }\end{array}$} & $\begin{array}{l}\text { I. Symptoms of } \\
\text { excessive gas, abnormal feeding, } \\
\text { duration of crying for I-3 hours/ } \\
\text { day and }>3 \text { hours/day at inclusion } \\
\text { were found in I } 7(85 \%) \text {, I } 5(75 \%) \text {, } \\
\text { I3 }(65 \%) \text {, and } 7(35 \%) \text { infants. }\end{array}$ & \multirow{4}{*}{$\mathrm{CC}$} \\
\hline & & & & $\begin{array}{l}\text { II. Intervention } \\
\text { significantly reduced each of the } \\
\text { symptoms }(p<0.0 \text { I). Symptoms } \\
\text { of excessive gas, abnormal } \\
\text { feeding, duration of crying for } \\
\text { I-3 hours/day and >3 hours/day } \\
\text { after intervention were found in } \\
5(25 \%), 6(30 \%), 3(15 \%) \text {, and } 0 \\
(0 \%) \text { infants. }\end{array}$ & \\
\hline & & & & $\begin{array}{l}\text { III. Approximately } 4 \\
\text { out of } 5 \text { patients who still had } \\
\text { symptoms of excessive gas were } \\
\text { crying for }<\text { I hour/day. }\end{array}$ & \\
\hline & & & & $\begin{array}{l}\text { IV. The level of } \\
\text { hydrogen expired in hydrogen } \\
\text { breath test decreased from } 35 \pm \\
\text { 3.I ppm at inclusion to } 10 \pm 2.5 \\
\text { Ppm }(p<0.0 \text { I) }\end{array}$ & \\
\hline
\end{tabular}

NNT, Number Needed to Treat; *, Calculation Used Secondary Outcomes; CC, Can't be Calculcated because Data were in Numerical Form

\section{Discussion}

Dietary modification is one of the most frequently used management strategies of infantile colic. Infants should be exclusively breast-fed for the first six months of life to achieve optimal growth, development, and health. In situations where infants can't suckle, expressed breast milk (mother own milk) or donor milk that meet safety requirement can be considered. ${ }^{14,15}$ If breast milk is not available, infants may be given formula milk which fulfills the Codex Alimentarius regulation with proper preparation of formula milk. ${ }^{14}$

The pathogenesis of infantile colic remains partly unknown. Several main factors are considered to cause colic symptoms, such as immaturity of nervous/digestive system, cow's milk proteins allergy and atopy, altered gut microflora such low Lactobacilli or increased E. Coli), and gut hormones such as increased ghrelin and motilin). ${ }^{16}$ From (Table 1) (Table 2), the colic symptoms improved in breastfed infants whose mothers consumed low-allergen diet (free of cow's milk, eggs, wheat, and nuts), and infants who received hydrolyzed casein/whey-based formula. This suggests that infantile colic can be triggered by food allergies, such as cow's milk allergy. The possible relationship between food allergy and infantile colic is based on two evidences, (1) the presence of dysmotility with visceral neuronal hypersensitivity and dysbiosis, and (2) the clinical response to dietary intervention. Although the etiology of infantile colic remains controversial, dysmotility and gut neuronal hyperexcitability have been advocated as pivotal pathogenetic factors. Food allergy induces gut neuronal hyperexcitability which lead to altered perception of physiological stimuli, such as intestinal distention and peristalsis, being perceived as painful events. ${ }^{17}$

Hypoallergenic maternal diet may be suggested in breast-fed infants. Meanwhile, partially hydrolyzed whey protein is the first line-approach and extensive hydrolyzed formula based on casein or whey could be useful in children with severe infantile colic or additional atopic symptoms. ${ }^{16,18,19}$ The use of hydrolyzed casein or whey-based formula led to the improvement of colic symptoms in infants, but Lothe et al. ${ }^{9}$ found that colic symptoms recurred in $75 \%$ of infants who received capsules containing whey protein powders extracted from cow's milk. This may be due to $\beta$-lactoglobulin which is the largest cow's milk allergen. In fact, $\beta$-lactoglobulin is the major component of whey protein in cow's milk, but it is not found in breast milk. ${ }^{20}$ In the confusion of using partially or extensive hydrolyzed formula, American Academy of Pediatrics (AAP) stated that partially hydrolyzed formulas are not hypoallergenic and should not be used for the dietary management of colic due to cow's milk protein allergy. ${ }^{21}$ Therefore, we suggest that low allergen maternal diet is effective in breast-fed colicky infants and extensive hydrolyzed formula based on casein or whey are effective in formula-fed infants due to the possibility of cow's milk allergy as the cause of infantile colic. Because some infants may still have colic symptoms after the consumption of whey protein, extensive hydrolyzed casein-based formula is preferably to manage infantile colic in formula-fed infants.

Campbel1 ${ }^{12}$ found that colic symptoms were significantly reduced during the consumption of soy protein-based formula, but only $5(17 \%)$ out of 19 subjects experienced spontaneous improvement. Cow's milk protein-based formula is the first choice for healthy and term infant who are not exclusively breast-fed, ${ }^{22}$ whereas soy proteinbased formula is indicated for infants with galactosemia, congenital lactase deficiency, or conditions in which parents prefer the vegetarian diet. ${ }^{23}$ European Society for Paediatric Gastroenterology Hepatology and Nutrition (EPSGHAN) ${ }^{22}$ and $\mathrm{AAP}^{23}$ suggest that the use of soy 
protein-based formula is not proven to prevent or manage infantile colic or fussiness in infants. Moreover, soy is an important allergen in infants because approximately $10-14 \%$ infants with cow's milk allergy will also have soy protein allergy. ${ }^{23}$ In 2009 , the Canadian Paediatric Society also stated that "physician should consider limiting the use of soy-based formulas to those infants with galactosemia or those who cannot consume dairy-based products for cultural or religious reasons. ${ }^{24}$ The use of low-lactose formula in the study by Infante et al. ${ }^{13}$ caused a significant reduction in the number of infants with excessive gas production, abnormal feeding pattern, and duration of crying, due to the inadequate study design. In contrary, there was no evidence of but those results should be considered carefully effect on excessive crying of lowering the lactose content of the formula milk..$^{25-27}$

\section{Conclusion}

Various studies have shown that nutritional intervention is one of the managements which can reduce the symptoms of colics in infants. Breast-fed mothers are advised to consume low-allergen diet, such as free of cow's milk, eggs, wheat and nuts to reduce the symptoms of infantile colic. In the other hand, infants who consume formula milk should be best given extensive hydrolyzed casein-based formula because colic symptoms may still persist after the consumption of whey protein. The use of soy protein-based formula and low-lactose formula does not have a strong evidence to reduce infantile colic symptoms in infants.

\section{Acknowledgements}

None.

\section{Conflict of interest}

Author declares that there is no conflict of interest.

\section{References}

1. Wessel MA, Cobb JC, Jackson EB, et al. Paroxysmal fussing in infancy, sometimes called colic. Pediatric. 1954;14(5):421-435.

2. Hyman PE, Milla PJ, Benninga MA, et al. Childhood functional gastrointestinal disorders: neonate/toddler. Gastroenterology. 2006;130(5):1519-1526.

3. Vandenplas Y, Gutierrez-Castrellon P, Velasco-Benitez C, et al. Practical algorithms for managing common gastrointestinal symptoms in infants. Nutrition. 2013;29(1):184-194.

4. Johnson JD, Cocker $\mathrm{K}$, Chang E. Infantile Colic: recognition and treatment. Am Fam Physician. 2015;92(7):577-582.

5. Jakobsson I, Lindberg T. Cow's milk proteins cause infantile colic in breast-fed infants: A double-blind crossover study. Pediatrics. 1983;71(2):268-271.

6. Hill DJ, Hudson IL, Sheffield LJ, et al. A low allergen diet is a significant intervention in infantile colic: Results of a community-based study. $J$ Allergy Clin Immunol. 1995;96(6 Pt 1):886-892.

7. Hill DJ, Roy N, Heine RG, et al. Effect of a low-allergen maternal diet on colic among breastfed infants: a randomized, controlled trial. Pediatrics. 2005;116(5):e709-715.
8. Lothe L, Lindberg T, Jakobsson I. Cow's milk formula as a cause of infantile colic: a double-blind study. Pediatrics. 1982;70(1):7-10.

9. Lothe L, Lindberg T. Cow's milk whey protein elicits symptoms of infantile colic in colicky formula-fed infants: a double-blind crossover study. Pediatrics. 1989;83(2):262-266.

10. Lucassen PLBJ, Assendelft WJJ, Gubbels JW, et al. nfantile colic: crying time reduction with a whey hydrolysate: a double-blind, randomized, placebo-controlled trial. Pediatrics. 2000;106(6):1349-1354.

11. Savino F, Palumeri E, Castagno E, et al. Reduction of crying episodes owing to infantile colic: a randomized controlled study on the efficacy of a new infant formula. Eur J Clin Nutr. 2006;60(11):1304-1310.

12. Campbell JPM. Dietary treatment of infant colic: a double blind study. $J$ $R$ Coll Gen Pract. 1989;39(318):11-14.

13. Infante D, Segarra O, Le Luyer B. Dietary treatment of colic caused by excess gas in infants: biochemical evidence. World J Gastroenterol. 2011;17(16):2104-2108.

14. WHO. Infant and young child nutrition. Global strategy on infant and young child feeding. Geneva: World Health Organization; 2002.

15. Walker S, Armstrong M. The four pillars of safe breast milk sharing. 2012 .

16. Savino F, Ceratto S, De Marco A, et al. Looking for new treatments of infantile colic. Ital J Pediatr. 2014;40:53.

17. Nocerino R, Pezzella V, Cosenza L, et al. The controversial role of food allergy in infantile colic: evidence and clinical management. Nutrients. 2015;7(3):2015-2025.

18. Critch JN. Infantile colic: Is there a role for dietary intervention? Paediatr Child Health. 2011;16(1):47-49.

19. Iacovou M, Ralston RA, Muir J, et al. Dietary management of infantile colic: A systematic review. Matern Child Health J. 2012;16(6):1319-1331.

20. Sélo I, Clément $\mathrm{G}$, Bernard $\mathrm{H}$, et al. Allergy to bovine betalactoglobulin: specificity of human IgE to tryptic peptides. Clin Exp Allergy. 1999;29(8):1055-1063.

21. American Academy of Pediatrics Committee on Nutrition. Hypoallergenic infant formulas. Pediatrics. 2000;106(2):346-349.

22. Agostoni C, Axelsson I, Goulet O, et al. Soy protein infant formulae and follow-on formulae: A commentary by the EPSGHAN Committee on Nutrition. J Pediatr Gastroenterol Nutr. 2006;42(4):352-361.

23. Bhatia J, Greer F, and the Committee on Nutrition. Use of soy proteinbased formulas in infant feeding. Pediatrics. 2008;121(5):1062-1068.

24. Leung A, Otley A. Canadian Paediatric Society, Nutrition Committee. Concerns for the use of soy-based formulas in infant nutrition. Paediatr Child Health. 2009;14(2):109-113.

25. Lucassen PLBJ, Assendelft WJJ, Gubbels JW, et al. Effectiveness of treatments for for infantile colic: systematic review. BMJ. 1998;316(7144):1563-1569.

26. Ståhlberg MR, Savilahti E. Infantile colic and feeding. Arch Dis Child. 1986;61(12):1232-1233.

27. Miller JJ, McVeagh P, Fleet GH, et al. Effect of yeast lactase enzyme on "colic" in infants fed human milk. J Pediatr. 1990;117(2 Pt 1):261-263. 